\title{
Prevention of rock burst by protective seam mining in high-depth strata: a case study
}

\author{
Enbing Yi \\ National Key Laboratory of Gas Disaster Detecting, Preventing and Emergency Controlling, \\ Chongqing, 400037, China \\ Chongqing Research Institute of China Coal Technology and Engineering Group, \\ Chongqing, 400037, China \\ E-mail: yienbing95@163.com
}

Received 22 June 2018; accepted 16 July 2018

DOI https://doi.org/10.21595/vp.2018.20043

Check for updates

Copyright $(2018$ Enbing Yi. This is an open access article distributed under the Creative Commons Attribution License, which permits unrestricted use, distribution, and reproduction in any medium, provided the original work is properly cited.

\begin{abstract}
Several rock burst accidents occurred during the excavation of the 4th seam in a mine. Based on the geological and mining conditions of the mine, numerical simulation methods was adopted to analysis the protective effect of the upper and lower protective seam mining on the 4th seam, and the causes of rock burst occurring in the roadway of LW 1410 was explained. Further, the characteristics of stress distribution in 6th seam and 1th seam was discussed, this is the bases for determining the protective effects of upper and lower protective seam mining, as well as the critical pressure relief angle and the critical pressure relief point location in the 4th seam. These parameters would provide meaningful information for optimizing the roadway layout and preventing rock burst in the subsequent face mining of 4th seam.
\end{abstract}

Keywords: rock burst; protective seam mining; numerical simulation; pressure relief zone.

\section{Introduction}

In order to prevent and control the disaster of rock burst, the technology of protective seam mining is one of the effective measures [1-7]. Many scholars have carried on extensive research on the principle and control technology of rock burst disaster, and have obtained remarkable outcomes [8-11]. Zhu Yue Ming et al. [12] discussed the feasibility of the steep seam protective seam mining in Wuchengjian mine, and provided a scientific basis for safe mining. Dou linming et al. [13] adopted field research, theoretical analysis, numerical simulation and in-site test method to study the principle of reducing load and reduction of thick seam sub-level caving mining. By increasing the mining thickness in a reasonable magnitude, the static load and the dynamic load would decrease after the implementation of the fault-top measure. Many scholars [14-17] have conducted researches on the early warning and monitoring of rock burst and protective seam mining, and have a pretty mature method for the law of overlying strata movement and the control of mine pressure. However, there are few researches on the prevention and control of rock burst by systematic analysis on the effects of protective seam mining on coal seam with high bursting liability. In this paper, the protective effect of the protective seam mining on the middle protected seam is studied on the bases of the geological and mining conditions of a coal mine.

\section{Survey of rock burst}

There are 6 seams that are available for mining, they are 1st, 4th, 6th, 13th, 15th, 16th coal seam. The highest depth of them are about $1200 \mathrm{~m}$, and the 4th seam is the main mining seam of the mine, sub-level caving mining is adopted in 1410 workface. More than 100 rock burst accidents have occurred in the mine, resulting in a lot of serious damage and even scrap, as well as casualties and serious impact on safe production.

According to the bursting liability test of 4th seam, its roof and bottom strata have strong bursting liability. Since the 1410 workface started caving, there have been many rock burst accidents on the workface. In order to reduce the threat of rock burst disaster, ensure the smooth 
caving of 4 th coal, the 6 th seam and 1 st seam are designed as protective mining seam for protecting the 4 th seam.

\section{Simulation method}

(1) Establishment of numerical model.

Along the tendency of coal seam model, the average inclination of coal strata is $31^{\circ}$. The model size is 460 by $450 \mathrm{~m}$ and the grid number is 380 by 326 . The depth of the top layer is about $820 \mathrm{~m}$, and the upper layer density is $2636 \mathrm{~kg} / \mathrm{m}^{3}$ on average, and the rocks above the top of the model are replaced by external load. The boundary conditions of the model are: no horizontal displacement at both ends, no vertical displacement at the bottom, and uniformly distributed load on the top, $r H=21.2 \mathrm{MPa}$; the initial conditions are: no displacement of coal seams, no movement, vertical stress caused by gravity, and gravity acceleration to $9.81 \mathrm{~m} / \mathrm{s}^{2}$. The numerical model is shown in Fig. 1.

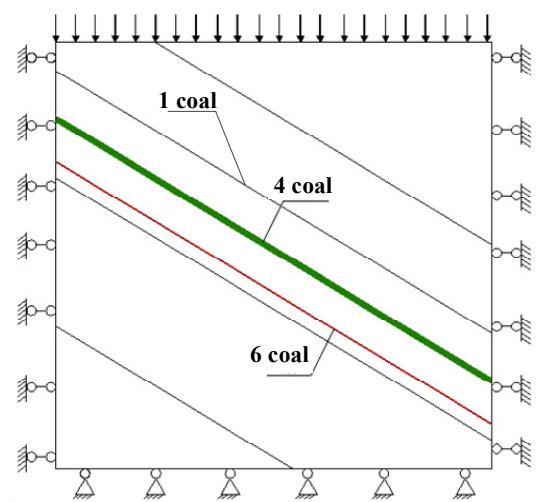

Fig. 1. Numerical calculation model

(2) Simulation scheme.

First of all, the stress relief effect of the 4th coal protected layer under the mining of 6 th coal protective layer was studied, especially the protective of 1610 surface and 1611 on the face of 1410 working surface. The reason of the impact pressure on the trough is analyzed through numerical simulation analysis, which provides guidance for future mining. By studying the protective effect of the 1st coal protective layer caving on the 4th coal protected layer in 1410 workface, the stress of the deep coal rock mass is reducing, and achieve the purpose of preventing the impact of the ground pressure.

\subsection{The influence of the lower protective layer mining on the protected layer in the middle.}

The horizontal projection of 1410 working face can be divided into two parts, which coincide with the working faces of 1611 and 1610 respectively. Therefore, it is necessary to simulate the protection of 1611 and 1610 in the different periods of the 1410 workface to study the protective effect of the excavation of 6th coal on the 1410 work surface. In the simulation process, the stress curve was made along the roof of 1410 working face, and the liberation effect of 1410 working face was analyzed with the mining analysis of 1611 and 1610 working face.

(1) The stress relief effects of 1610 working face on 1410 working face.

The simulation results show that: the stress in the horizontal roadway of the 1410 working face is lower in the range of $22 \mathrm{~m}$, but the change is not large. After $22 \mathrm{~m}$, the stress increases rapidly. After $45 \mathrm{~m}$, the vertical stress exceeds the original rock stress. After mining of 1610 working face, the stress of the surrounding rock in the roadway area of 1410 working face was relieved. The inclination angle of the upper and lower boundary of protected areas and 6th coal are $60^{\circ}$ and $80^{\circ}$ 
respectively. The change of roof crushing and ionosphere is large. It indicates that the liberated layer 4th coal can be fully relieving after the mining of 6th coal protective layer.

(2) The stress relief effects of 1611 working face on 1410 working face.

The simulation results show that: the upper level drift of 1410 was not in the protected area of 1611 , and over time, the stress in the protected area of 1610 gradually recovered, and reached the maximum stress at $31 \mathrm{~m}$, exceeding the original rock stress. Under the influence of coal pillar, stress concentration appears in the area above the pillar. After the stress peak of the right liberation area on the upper level drift, the stress down the lower level drift is gradually decreasing, and the protective effect of 1611 is obvious after $50 \mathrm{~m}$. The lower level drift is in the protected area of 1611 working face, the relief effect is obvious.

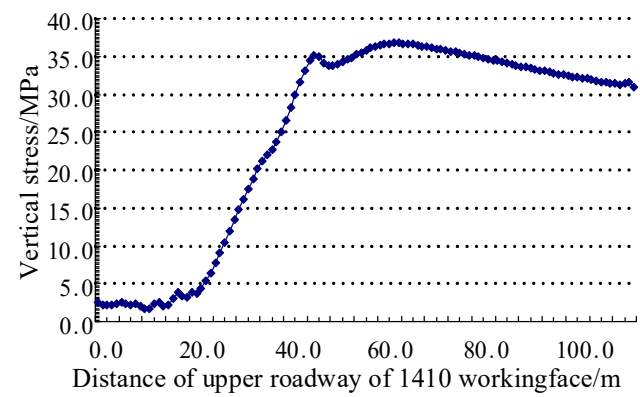

Fig. 2. The vertical stress on workface 1410 of workface 1610 mining

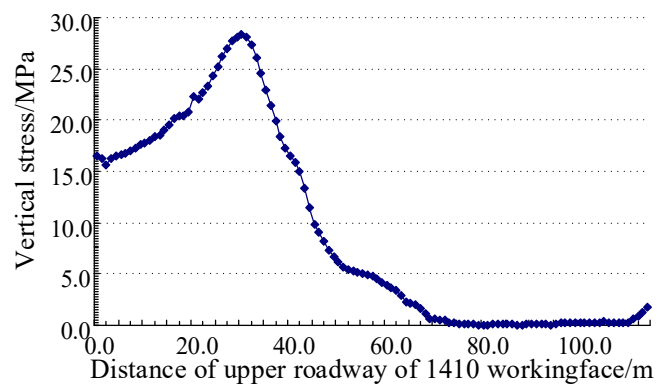

Fig. 3. The vertical stress on workface 1410 of workface 1611 mining

(3) The stress relief effects of the upper and lower protective seam excavation on 1410 working face.

The simulation results show that: after the excavation of the upper and lower level drift in 1410 working face, the maximum vertical stress in the $5 \mathrm{~m}$ wide coal pillar between 1409 working face and 1410 working face is close to $30 \mathrm{MPa}$ without stress concentration. High stress concentration area appears on the right side of the upper level drift, the maximum stress is close to $60 \mathrm{MPa}$, and the stress peak appears at about $8 \mathrm{~m}$ from the roadway. On the right side of the roadway, the vertical stress is greater than that of the original rock. The tension stress failure zone near the lower level drift shows a better effect of pressure relief.

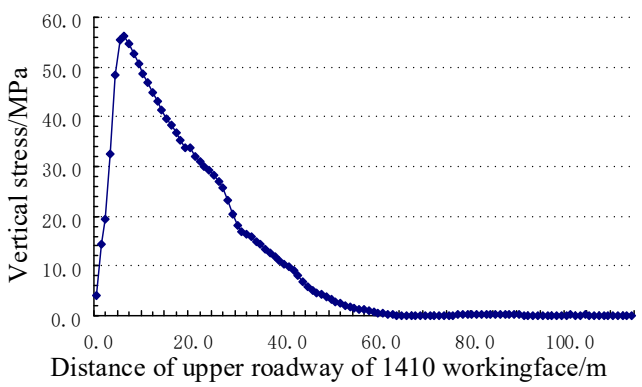

Fig. 4. The vertical stress after the excavation of the upper and under roadway of work face 1410

\section{The pressure relief effect on the protected layer}

The key to safe mining in thick coal seam with strong rock burst is to control the occurrence of rock burst disaster. Therefore, the relationship between mining technology and rock burst is the first subject to be studied. This paper studies the quantitative evaluation method of the rock burst risk of the mining in protective and protected layer based on the 1411 working face. Finally, it is applied to the deep mining level of the mine. 


\subsection{The simulation evaluation of the liberation effect on liberated layer}

(1) Analysis of the cause of rock burst not occurred in 1409 working face.

The working face was pushed up to $150 \mathrm{~m}$, equivalent to the mining of 1609 and 1610 working face. As can be seen from Fig. 5, the 1409 working face is located in the pressure relief area without the mechanical conditions of catastrophic rock burst. The two decreasing region near the gate roadway and the increasing region in the middle of the working face are marked.

(2) Analysis of the cause of rock burst in 1410 working face.

Fig. 6 is a schematic diagram of the relief area and increasing area caused by rock strata movement while working face pushed to $260 \mathrm{~m}$. From that we can find, there is a common support point of rock structure on the top of lower and upper level drift in 1410 working face at 6th mined-out area. The high stress area is formed and the rock burst is easy to occur in the region. The hard and thick layers of 6th coal roof are slowly sinking.

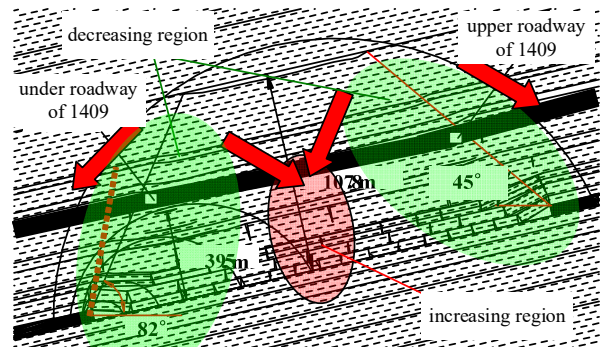

Fig. 5. The distribution diagram of

stress-relaxed area and stress-increasing area after a mining distance of $150 \mathrm{~m}$

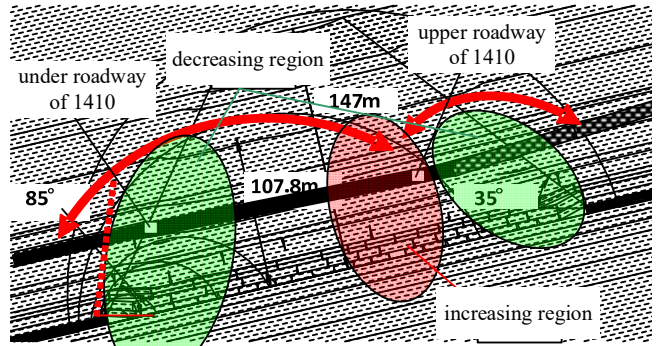

Fig. 6. The distribution diagram of

stress-relaxed area and stress-increasing area after a mining distance of $260 \mathrm{~m}$

(3) Analysis of the cause of rock burst in 1410 working face.

When the 1411 working face is actually mined, the 6 th coal protective layer has been recovered. In the simulation, and the 6th coal protective layer promoted $320 \mathrm{~m}$. In order to be able to clearly see the distribution of roof structure and stress recovery area in goaf, the rock strata in the upper level drift of the 6th coal protective layer are removed, and only the lower strata structure is retained. The lower roadway of the 1411 working face is in the relief area, while the upper level is in the high stress region, namely the stress recovery zone of the protective layer and the superimposed area of the lateral supporting pressure of the coal pillar of 1410 working face. Therefore, it is in serious danger of rock burst.

(4) Analysis of rock strata movement rule.

The movement evolution and destruction of the mining overburden space structure are the root causes of various disasters, such as the rock burst of the working face, the water bursting of the roof and floor and the surface subsidence. Therefore, it is the foundation of mine pressure control to understand the movement rule of rock strata comprehensively. When the working face is advanced to $40 \mathrm{~m}$, the structure height of the mining overburden is about $18 \mathrm{~m}$. When the working face is advanced to $70 \mathrm{~m}$, the structure height of the mining overburden is about $39.5 \mathrm{~m}$. This stage is the first hard rock to prevent the extension of the fracture. When the working face continued to advanced to $150 \mathrm{~m}$, the structure of the mining overburden structure suddenly developed to $107.8 \mathrm{~m}$. In the process of the working face advanced $150-250 \mathrm{~m}$, the spatial structure of the mining overburden was maintained at $107.8 \mathrm{~m}$. When the working face continued to reach $260 \mathrm{~m}$, the height of the mining overburden space structure changed to $147 \mathrm{~m}$ suddenly. In the process of the working face advanced $260 \mathrm{~m}-310 \mathrm{~m}$, the spatial structure of the mining overburden was maintained at $147 \mathrm{~m}$. When the working face continued to reach $320 \mathrm{~m}$, the height of the mining overburden space structure changed to $176 \mathrm{~m}$. The relationship between the advance distance and the spatial structure of the mining overburden can be expressed in Fig. 7. In the figure, the horizontal coordinate is the advance distance, and the vertical axis is the height of the mining 
overburden space structure. In the stage of non-full mining, the spatial structure of the mining overburden is linearly increased with the working face. The platform in the figure illustrates the role of thick hard rock, as well as the temporary or periodic effect of heavy hard rock, known as the "thick hard rock effect platform".

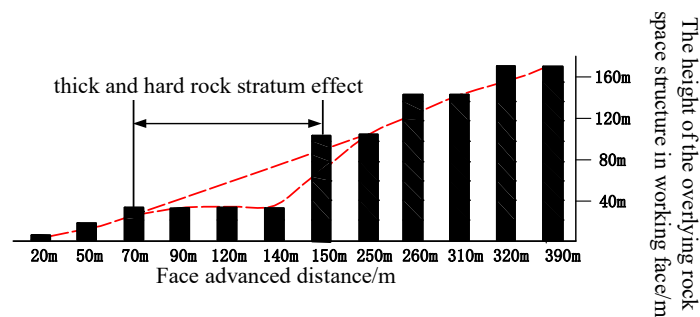

Fig. 7. The evolvement of spatial structure height of mining overlying strata with face advance

Fig. 7 reveals the dynamic pressure mechanism on the formation of working face once and twice "Jianfang". The distance between 140 and $150 \mathrm{~m}$ is the equivalent of a working face "Jianfang", the rupture height of rock strata suddenly increased from $39.5 \mathrm{~m}$ to $107.8 \mathrm{~m}$, forming a dynamic pressure.

\subsection{Microseismic evaluation of protective effect in protected layer}

Before the mining of 1409 working face, the fracture morphology of rock strata in the 1609 and 1610 working face is shown in Fig. 9. The lower level drift of 1409 working face is in pressure relief region and the hard rock strata in the bottom of the upper drift are not broken. The effective protection height of the under protected layer is $60-100 \mathrm{~m}$, effectively protect depth of floor is about $40 \mathrm{~m}$, the under protective angle (intensive damage area) is $71^{\circ}$, edge rupture angle is $82^{\circ}$.

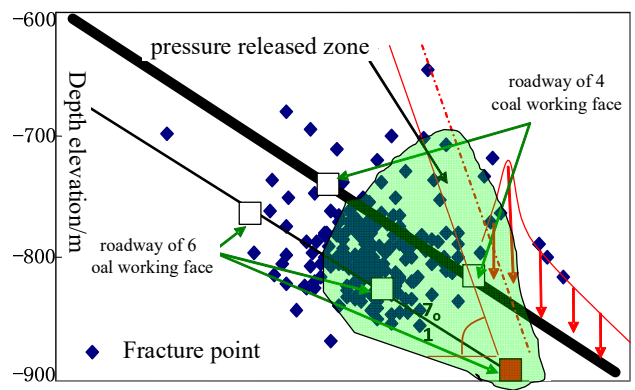

Fig. 8. Measured drawing of protected areas after excavation of six liberated seams

\section{Conclusions}

In this paper, the time effect of protective effect of mining liberation is explained. If the protected area dose not form caving or crack destruction, but only pressure relief through the deformation, the stress of the protected area will gradually recover over time. The cause of the rock burst on the upper level drift of 1410 working face has been analyzed. The surrounding rock of roadway is in constant stress concentration and release state, and the stress gradient is large, and the surrounding rock of roadway is constantly being squeezed, expanded and even reversed. When the stress of lateral support and advanced support in the process of roadway driving or working face increase the stress of surrounding rock, it may induce the impact of the roadway. In the process of mining, the coal seam inclination and the retention of coal pillar have in protected area great influence on the protective effect of the corresponding zone. The roadway design of the liberated layer should be as reasonable as possible to avoid the excavation roadway in the area 
where the stress concentration is likely to occur. The "lateral stress recovery zone" exists at the top of the working face goaf of the lower protective layer after the lower liberation layer is mined. When the mining depth exceeds the depth of the rock burst limit, there is still the possibility of rock burst in the protected roadway.

\section{Acknowledgements}

This research is supported by the National Key Research and Development Program of China (2017YFC0804208); National Natural Science Foundation of China (51604298).

\section{References}

[1] Zhang Xiangyang, Tu Min, Yang Ke, et al. Determination on rational location of final terminal mining line for protective seam pressure releasing and mining in two seams. Coal Science and Technology, Vol. 40, Issue 2, 2012, p. 15-18.

[2] Tang Zhi, Pan Yishan, Li Zhonghua, et al. Numerical simulation on destressing effects of the deep thick coal seam with high burst liability after mining liberated seams. The Chinese Journal of Geological Hazard and Control, Vol. 22, Issue 1, 2001, p. 128-132.

[3] Wang Luofeng, Jiang Fuxing, Yu Zhengxing Similar material simulation experiment on destressing effects of the deep thick coal seam with high burst liability after mining upper and lower protective seams. Chinese Journal of Geotechnical Engineering, Vol. 31, Issue 3, 2009, p. 442-446.

[4] Wu Xiangqian, Dou Linming, Zheng Youlei, et al. Study on upper liberated seam mining to pressure releasing function of low seam. Coal Science and Technology, Vol. 40, Issue 3, 2012, p. 28-31.

[5] Pang Longlong, Xu Xuefeng, Si Liang, et al. Analysis of prevention mechanism of upper protective seam mining on rock rockburst induced by thick conglomerate. Coal Science and Technology, Vol. 37, Issue 2, 2012, p. 120-128.

[6] Zhang Jingmin, Liu Zhentang, Xie Long Research on pressure relief effects of protective layer under the conditions of coal seam group mining. Safety in Coal Mines, Vol. 43, Issue 9, 2012, p. 14-16.

[7] Lv Changguo, Dou Linming, Xu Changhou, et al. Numerical simulation of protective mechanism of upper protective seam mininig. Coal mining Technology, Vol. 16, Issue 2, 2011, p. 12-15.

[8] Dou Linming, He Jiang, Cao Anye, et al. Rock burst prevention methods based on theory of dynamic and static combined load induced in coal mine. Journal of Mining and Safety Engineering, Vol. 40, Issue 7, 2015, p. 1469-1476.

[9] Kou Jianxin, Gong Siyuan Research on risk assessment of rock burst in working face through mine CT technology. China Coal, Vol. 39, Issue 11, 2013, p. 55-60.

[10] Dou Linming, Jiang Yaodong, Cao Anye, et al. Optimization analysis of drilling layout based on blasting releasing pressure and its applicationmonitoring and pre-warning of rockburst hazard with technology of stress field and wave field in underground coalmines. Chinese Journal of Rock Mechanics and Engineering, Vol. 36, Issue 4, 2017, p. 1469-1476.

[11] Hu Zhaofeng, Liu Jinliang, Li Xingdong, et al. Prevention and practices on mine rock burst from seam with high burst tendency in over $1000 \mathrm{~m}$ deep mine. Coal Science and Technology, Vol. 41, Issue 4, 2013, p. 36-39.

[12] Zhu Yue Ming, Pan Yi Shan, Sun Ke Ming Physical modeling experiment of extraction of protective seam in dip-slopping coal seams. Journal of Liaoning Technical University, Vol. 22, Issue 2, 2003, p. 205-207.

[13] Dou Linming, Li Zhenlei, He Xueqiu Principle of rockburst control by weakening static and dynamic loading using top-coal caving in the mining of thick coal seams. Journal of China University of Mining andTechnology, Vol. 47, Issue 2, 2018, p. 221-230.

[14] He Hu, Sun Hao, Wang Qian Electromagnetic emission-microseismicity coupling evaluation method for rockburst. Journal of China Coal Society, Vol. 43, Issue 2, 2018, p. 364-370.

[15] Dou Linming, He Hu, He Jiang, et al. New method of rockburst risk assessment using relative stress concentration factor superposition. Journal of China Coal Society, Vol. 43, Issue 2, 2018, p. 327-332.

[16] Jiang Fuxing, Yang Shuhua, Cheng Yunhai, et al. A study on microseismic monitoring of rock burst in coal mine. Chinese Journal of Geophysics, Vol. 49, Issue 5, 2006, p. 1511-1516.

[17] Lan Hang, Du Taotao Monitoring and analysis of rock burst process during steeply inclined and ultra thick seam mining. Coal Science and Technology, Vol. 44, Issue 6, 2016, p. 78-82. 